\title{
Planar Relationships of the Semicircular Canals in Two Strains of Mice
}

\author{
Daniel R. Calabrese and Timothy E. Hullar \\ Department of Otolaryngology—Head and Neck Surgery, Washington University School of Medicine, 660 South Euclid \\ Avenue \#8115, Saint Louis, MO 63110, USA
}

Received: 2 August 2005; Accepted: 27 February 2006; Online publication: 22 April 2006

\begin{abstract}
The mouse is increasingly important as a subject of vestibular research. Although many studies have focused on the vestibular responses of mice to angular rotation, the geometry of their semicircular canals has not been described. High-voltage X-ray computed tomography was used to measure the anatomy of the semicircular canals of two strains of mice, $\mathrm{C} 57 \mathrm{Bl} / 6 \mathrm{~J}$ and $\mathrm{CBA} / \mathrm{CaJ}$. The horizontal plane of a stereotaxic coordinate system was defined by the midpoints of the external auditory meati and the point where the incisors emerge from the maxilla. The centroids of the lumens of the bony canals were calculated, and planes that describe the canals were fit using a least-squares regression analysis to the resulting points. Vectors normal to each regressed plane were used to represent the corresponding canal's axis of rotation, and angles of these vectors relative to skull landmarks as well as to each other were calculated. The horizontal canal of the mouse was found to be angled anteriorly upward $17.8^{\circ}$ for $\mathrm{CBA} / \mathrm{CaJ}$ and $32.6^{\circ}$ for $\mathrm{C} 57 \mathrm{Bl} / 6 \mathrm{~J}$ from the reference horizontal plane. Angles between ipsilateral canals deviated up to $12.3^{\circ}$ from orthogonal, and angles between contralateral synergistic canals (left anterior-right posterior, right anterior-left posterior, and horizontal-horizontal) deviated from parallel by up to $14.8^{\circ}$. The orientations of the canals within the head as well as the orientations of the canals relative to each other were significantly different between the
\end{abstract}

Correspondence to: Timothy E. Hullar · Department of Otolaryngology-Head and Neck Surgery · Washington University School of Medicine $\cdot 660$ South Euclid Avenue \#8115, Saint Louis, MO 63110, USA. Telephone: +1-314-6298082; fax: +1-314-3627522; email: hullart@ent.wustl.edu two strains, suggesting that care must be taken in the design and interpretation of developmental and physiologic studies involving different mouse strains.

Keywords: vestibular, afferent, vestibulo-ocular reflex, VOR, micro CT, labyrinth

\section{INTRODUCTION}

The mouse is an increasingly attractive subject for vestibular research, as more strains of mutant mice with abnormalities of the vestibular system become available (Ahituv and Avraham 2000; Anagnostopoulos 2002). Eye movement studies of mice have become routine (Koekkoek et al. 1997; De Zeeuw et al. 1998; Stahl et al. 2000; van Alphen et al. 2001; Stahl, 2004), and mouse afferent recordings have been reported both from intact animals (Park et al. 2005) and preparations using the isolated labyrinth (Lee et al. 2005).

Anatomic studies have revealed that some mouse mutants, such as Otx1 (Acampora et al. 1996), Ecl (Cryns et al. 2004), Whl (Alavizadeh et al. 2001), Obt, Todo, Dz, Cyn, Edy, Mt, and Lda (Kiernan et al. 2002), and Crsl and Whi (Hawker et al. 2005), show gross changes in the bony semicircular canals. In contrast, others, such as stargazer (Khan et al. 2004), het (Paffenholz et al. 2004), isk (Vetter et al. 1996), tlt and mlh (Hurle et al. 2003), Pmca2 (Kozel et al. 1998), shaker/waltzer (Sun 2001), and hscy (Longo-Guess et al. 2005), have not been reported as having significant bony abnormalities. It is not known, however, if some of these animals may have relatively subtle changes in the anatomy of the temporal bone that have gone unnoticed. As the expected labyrinthine geometry (and, in particular, the orientations 
of the semicircular canals) in normal mice has not been described, no baseline exists against which these animals may be closely compared to evaluate them for such changes.

Studies attempting to maximize the response of a particular semicircular canal to head rotations require that the plane of the canal be placed in the plane of rotation. A stereotaxic needle held in a micromanipulator has been used to determine the planar geometry of the semicircular canals in several species, including rhesus and squirrel monkey (Blanks et al. 1985; Haque et al. 2003), turtle (Brichta et al. 1988), rabbit (Ezure and Graf 1984; Mazza and Winterson 1984), guinea pig (Curthoys et al. 1975), rat (Blanks and Torigoe 1989), and man (Blanks et al. 1975a). This technique, however, is unlikely to be practical or accurate for an animal as small as the mouse. In the toadfish (Ghanem et al. 1998) and in humans (Sato et al. 1992; Hashimoto 2003), histologic preparations have been used to measure the dimensions of the semicircular canals as well as their anatomic planes within the skull. This technique has the advantage of allowing visualization of both the membranous duct and the bony canal, but is relatively time consuming and may be liable to shrinkage error during preparation or difficulty sectioning the specimen and registering the photographic images of histologic slices. Recently, computed tomography (Della Santina et al. 2005) and magnetic resonance images (Ichijo 2002) have also been used to estimate the canal planes in man.

High-voltage X-ray computed tomography, or microCT, is a recently developed technology that offers certain advantages over these previous techniques. MicroCT allows exact image registration with isotropic voxel dimensions as small as $6 \mu \mathrm{m}$ per side (with the exact voxel dimension depending on the size of the object of interest). Here, we describe the orientations of the semicircular canals in two strains of mice using microCT technology. The results will provide a baseline against which mice with anatomic anomalies of the vestibular system may be compared and allow for more accurate positioning for physiologic testing of these increasingly important research animals.

\section{METHODS}

Analyses were conducted on four skulls of adult ( $>8$ weeks) $\mathrm{C} 57 \mathrm{Bl} / 6 \mathrm{~J}$ mice and four skulls of adult $\mathrm{CBA} / \mathrm{CaJ}$ mice obtained from Jackson Laboratory (Bar Harbor, ME, USA). C57Bl/6J is an inbred strain commonly used in biomedical research, including ear research, although it suffers from genetically related presbycusis (Johnson et al. 2000). The $\mathrm{CBA} / \mathrm{CaJ}$ strain is also commonly used in research but does not suffer from the same hearing loss and is therefore particularly attractive for studies of the ear. The mice used here had been previously sacrificed without perfusion and prepared by manually removing the nonosseous tissue before gradual drying. The suture lines of the skulls of adult mice are not fused, and a possibility exists that the elements of the skull may have shifted during the drying process leading to erroneous measurements. To minimize this possibility, the skulls were kept intact, including the mandible and its supporting musculature and ligaments, during the drying process. All specimens were dried gradually, leading to a final product that remained symmetric and showed no evidence of warping. Prepared specimens were scanned in a microCT scanner (micro40, Scanco, Bassersdorf, Switzerland), which produced a series of coronal sections with isotropic voxels measuring $16 \mu \mathrm{m}$ per side (Fig. 1). Voxel size was determined by the scanner software based on the bore diameter $(16 \mathrm{~mm})$ of the smallest scanner tube able to fit the mouse skulls. The resulting threedimensional images were visualized using VideoMach (http://www.gromada.com/) and Volocity (http:// www.improvision.com/). Each semicircular canal was traced using custom-written software in Matlab (http://www.themathworks.com/, Natick, MA, USA). Individual bony canals were located as they passed through each slice, and the centroid of each canal's lumen was calculated. The centroids were determined for each canal from the ampulla through to the point where it reentered the vestibule (including the common crus for posterior and anterior canals). The canals were digitized using every slice up to the point where the two elliptical lumens of a particular semicircular canal joined into a single ellipse as the

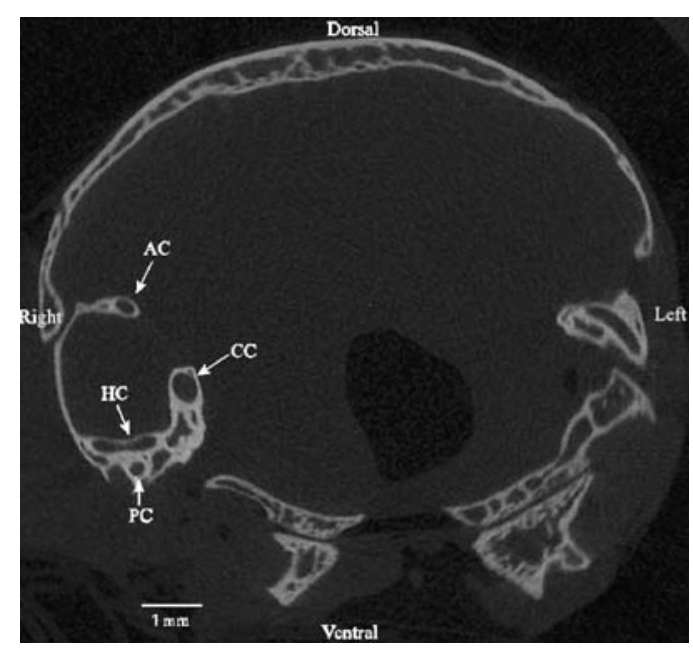

FIG. 1. Image of a scanned microCT slice for a mouse of strain $\mathrm{CBA} / \mathrm{CaJ}$. Canals on the animal's right side are labeled as follows: $\mathrm{AC}$, anterior canal; CC, common crus; HC, horizontal canal; PC, posterior canal. 

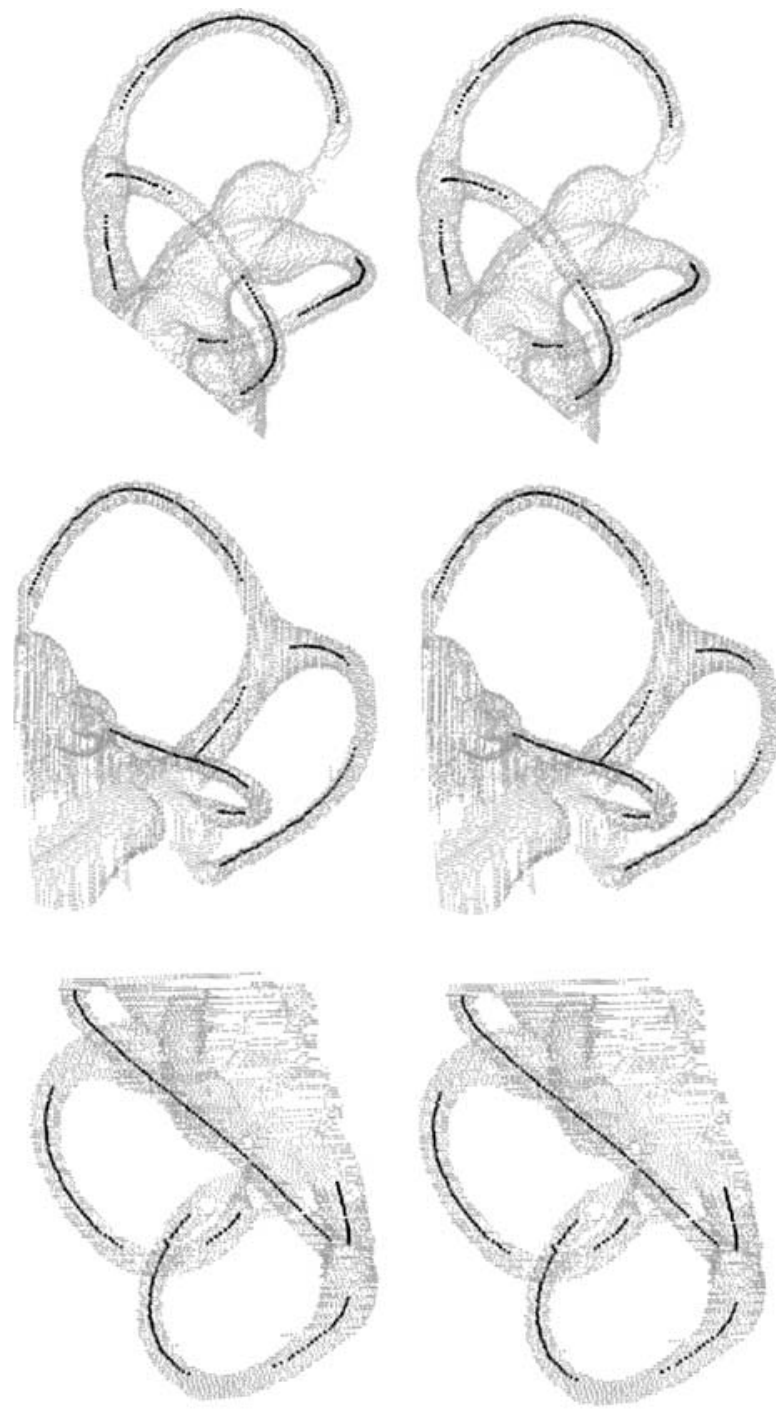

$1 \mathrm{~mm}$

FIG. 2. Stereoscopic representations of the left labyrinth of a mouse of strain CBA/CaJ. Outlines of bony canals are shown in gray, whereas centroids of canal lumens are represented with black dots. Top row: front view with animal facing reader; middle row: lateral view with animal facing to the left; bottom row: dorsal view with animal facing to top of page (identical to views in Fig. 4). To achieve three-dimensional effect, initially, view each row at extremely close range and allow each eye to focus on one image only. Slowly lengthen viewing distance until three images are present. The center image is a three-dimensional representation of the labyrinth.

canal became tangent to the scanning slice (Fig. 2). This technique does not sample the semicircular canal's circumference perfectly regularly, but previously published methods have resulted in similar small irregularities while still producing reliable results (Dickman 1996), and a comparison of results obtained using this technique to an alternative using lumens from every slice had an insignificant effect on the orientation of the canal's plane. Reference points on the skull, including lambda, bregma, the midpoint of the posterior insertion of the maxillary incisors into the maxilla, and the midpoint of the external auditory canals, were also identified.

The data points were initially oriented in an arbitrary frame of reference defined by the position of the skull in the CT scanner. To allow comparison among specimens, a uniform stereotaxic reference frame was chosen with a horizontal plane defined by the centers of the left and right auditory meati and the point where the posterior edges of the incisors emerge from the maxillary bone. This reference plane has been used previously in rodents (Sherwood and Timiras 1970; Curthoys et al. 1975). Coordinates representing each data point were adjusted using the appropriate rotation matrices necessary to align the animal's skull into a standard right-handed $x y z$ coordinate system, with the positive $x$-axis projecting out of the nose, the positive $y$-axis projecting out of the left ear, and the positive $z$-axis projecting dorsally. The origin of the three axes was defined by the midpoint of the interaural line.

Canal planes were determined using a leastsquares fit regression of a plane to the digitized centroids of each canal's lumen (Fig. 3). The center of curvature of each canal was determined from the digitized centroids using a least-squares fit to a circle, and the radius of curvature was calculated by averaging the distance from the canal's center to the projection of each of the digitized points onto

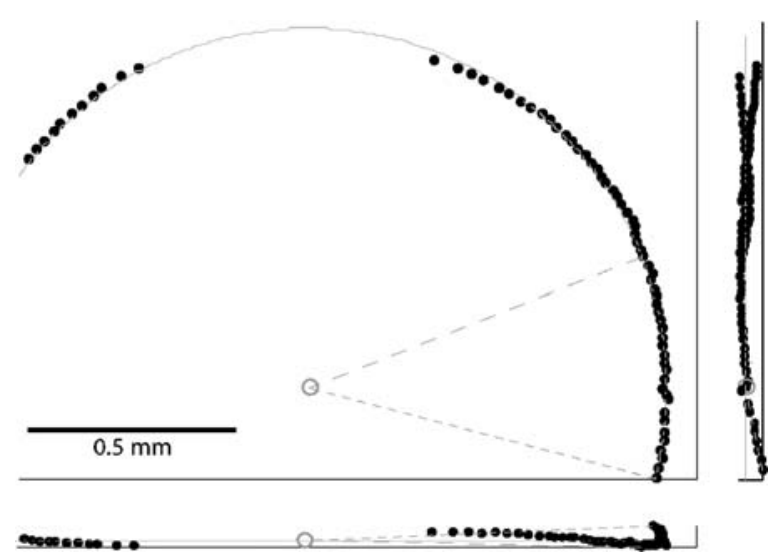

FIG. 3. Plan and elevation views of representative canal (posterior canal from labyrinth depicted in Fig. 2). The canal is depicted so that the best-fit plane to the data is parallel to the page in the plan view (upper left). Orthogonal elevation views are at right and below. Black dots: centroids of canal lumens; gray arc: curve fitted to centroids; small gray circle: center of fitted curve; dotted gray line: vector between fitted center and point giving greatest angle upward out of the canal plane; dashed gray line: vector between fitted center and point giving greatest angle downward out of the canal plane. Gap in data points reflects region where scanned slices were tangent to the curve of the canal and the centroids of the lumen could not be reliably determined, as discussed in the text. 


\begin{tabular}{lccc}
\hline \multicolumn{4}{c}{ TABLE 1} \\
\hline \multicolumn{4}{c}{ Dimensions of the semicircular canals } \\
\hline & ArC $\left(\right.$ in $\left.^{\circ}, \pm S D\right)$ & $\begin{array}{c}C 57 \mathrm{~B} / / 6) \text { radius } \\
( \pm S D)\end{array}$ & $\begin{array}{c}C B / C \text { al radius } \\
( \pm S D)\end{array}$ \\
\hline $\mathrm{HC}$ & $136.1^{\circ} \pm 15.2^{\circ}$ & $0.725 \pm 0.026$ & $0.693 \pm 0.065$ \\
$\mathrm{AC}$ & $164.4^{\circ} \pm 9.7^{\circ}$ & $1.032 \pm 0.019$ & $1.063 \pm 0.021$ \\
$\mathrm{PC}$ & $159.5^{\circ} \pm 11.2^{\circ}$ & $0.820 \pm 0.033$ & $0.822 \pm 0.027$ \\
\hline
\end{tabular}

Arc formed by the centroids of each canal averaged across both strains of mice $(n=8)$. Average radii of curvature $(\mathrm{mm})$ for each canal analyzed separately by strain $(n=4$ per strain). No significant difference in radius is evident $(p>0.1)$ when comparing each canal's radius between strains.

$\mathrm{HC}$, horizontal canal; AC, anterior canal; PC, posterior canal.

the canal plane. The angles between the canal plane and the vector connecting the canal's center to each digitized centroid were also calculated. The maximum angles above and below the plane were summed to create a measure of the relative planarity of the canal, as previously described (Blanks et al. 1985). Vectors representing each canal's orientation were determined by calculating a unit vector normal to each canal plane, with the polarity of the vector corresponding to the excitatory direction of rotation of the canal via the right-hand rule. The angle between pairs of canals was determined by calculating the arccosine of the dot product of each canal's unit vector (Ezure and Graf 1984). In addition, the "prime direction" for each canal was calculated. A canal's prime direction is the cross product of the vectors defined by the canal's two ipsilateral canals, with a rotation about the prime direction vector theoretically resulting in no response from the ipsilateral canals. Angles between the prime vectors were calculated in the same manner as the angles between the vectors normal to the canal planes.

\section{RESULTS}

In the $\mathrm{C} 57 \mathrm{Bl} / 6 \mathrm{~J}$ mice, the interaural distance was $9.5 \pm$ $0.17 \mathrm{~mm}$, and the distance from the incisors to the

\section{TABLE 3}

Average $X, Y$, and $Z$ components of normal unit vectors for $\mathrm{CBA} / \mathrm{CaJ}$ mice and $\mathrm{C} 57 \mathrm{Bl} / 6 \mathrm{~J}$ mice

\begin{tabular}{lcrr}
\hline Canal & $X \pm S D$ & $Y \pm S D$ & $Z \pm S D$ \\
\hline CBA/CaJ mice $(n=4)$ & & \\
RHC & $0.306 \pm 0.041^{\mathrm{a}}$ & $-0.071 \pm 0.029$ & $-0.948 \pm 0.010^{\mathrm{a}}$ \\
RAC & $0.646 \pm 0.027$ & $0.718 \pm 0.018$ & $0.254 \pm 0.019^{\mathrm{a}}$ \\
RPC & $0.586 \pm 0.026^{\mathrm{a}}$ & $-0.665 \pm 0.034^{\mathrm{a}}$ & $0.460 \pm 0.032^{\mathrm{a}}$ \\
LHC & $-0.334 \pm 0.076^{\mathrm{a}}$ & $-0.080 \pm 0.092$ & $0.932 \pm 0.027^{\mathrm{a}}$ \\
LAC & $-0.632 \pm 0.023$ & $0.717 \pm 0.022$ & $-0.290 \pm 0.015$ \\
LPC & $-0.553 \pm 0.030^{\mathrm{a}}$ & $-0.675 \pm 0.033^{\mathrm{a}}$ & $-0.485 \pm 0.027$
\end{tabular}

C57Bl/6J mice $(n=4)$

\begin{tabular}{lcrr} 
RHC & $0.536 \pm 0.035^{\mathrm{a}}$ & $-0.085 \pm 0.042$ & $-0.838 \pm 0.024^{\mathrm{a}}$ \\
RAC & $0.601 \pm 0.036$ & $0.716 \pm 0.057$ & $0.344 \pm 0.063^{\mathrm{a}}$ \\
RPC & $0.346 \pm 0.086^{\mathrm{a}}$ & $-0.769 \pm 0.054^{\mathrm{a}}$ & $0.529 \pm 0.032^{\mathrm{a}}$ \\
LHC & $-0.521 \pm 0.101^{\mathrm{a}}$ & $-0.053 \pm 0.063$ & $0.843 \pm 0.067^{\mathrm{a}}$ \\
LAC & $-0.596 \pm 0.098$ & $0.702 \pm 0.068$ & $-0.369 \pm 0.063$ \\
LPC & $-0.350 \pm 0.025^{\mathrm{a}}$ & $-0.783 \pm 0.069^{\mathrm{a}}$ & $-0.500 \pm 0.106$ \\
\hline
\end{tabular}

$n=4$ per strain.

RHC, right horizontal canal; RAC, right anterior canal; RPC, right posterior canal; LHC, left horizontal canal; LAC, left anterior canal; LPC, left posterior canal.

aStatistically significant difference in component length between strains; ANOVA, $p<0.05$.

interaural line was $15.2 \pm 1.10 \mathrm{~mm}$. In the $\mathrm{CBA} / \mathrm{CaJ}$ mice, the interaural distance was $8.6 \pm 0.09 \mathrm{~mm}$, and the distance from the incisors to the interaural line was $14.7 \pm 0.22 \mathrm{~mm}$. In the population studied, the traced centroids of the canals formed an arc of $164.4^{\circ} \pm 9.7^{\circ}$ for the anterior canals, an arc of $159.5^{\circ} \pm$ $11.2^{\circ}$ for the posterior canals, and an arc of $136.1^{\circ} \pm$ $15.2^{\circ}$ for the horizontal canals. The radii of curvature of the semicircular canals are shown in Table 1. Comparisons between strains indicate that there is no significant difference in the radii of particular canals between the tested strains of mice [analysis of variance (ANOVA), $p>0.1]$. However, pairwise comparison among the radii of ipsilateral canals reveals a significant difference in both strains (ANOVA, $p<$ $0.05)$, with the anterior canals larger than the

TABLE 2

\begin{tabular}{|c|c|c|c|c|c|c|}
\hline \multicolumn{7}{|c|}{ Center of canals for $\mathrm{CBA} / \mathrm{CaJ}$ and $\mathrm{C} 57 \mathrm{Bl} / 6 \mathrm{~J}$ mice in $\mathrm{mm}$, relative to origin defined as center of interaural line } \\
\hline \multirow[b]{2}{*}{ Canal } & \multicolumn{3}{|c|}{ CBA/Cal mice $(n=4)$} & \multicolumn{3}{|c|}{ C57Bl/6J mice $(n=4)$} \\
\hline & $X \pm S D$ & $Y \pm S D$ & $Z \pm S D$ & $X \pm S D$ & $Y \pm S D$ & $Z \pm S D$ \\
\hline RHC & $-1.43 \pm 0.06$ & $-3.42 \pm 0.10^{\mathrm{a}}$ & $0.84 \pm 0.13^{a}$ & $-1.62 \pm 0.30$ & $-3.65 \pm 0.15^{\mathrm{a}}$ & $0.53 \pm 0.01^{\mathrm{a}}$ \\
\hline RAC & $-1.30 \pm 0.05$ & $-3.35 \pm 0.10^{\mathrm{a}}$ & $1.59 \pm 0.13$ & $-1.65 \pm 0.39$ & $-3.46 \pm 0.09^{\mathrm{a}}$ & $1.35 \pm 0.28$ \\
\hline RPC & $-2.18 \pm 0.06$ & $-3.00 \pm 0.03^{\mathrm{a}}$ & $1.02 \pm 0.13^{a}$ & $-2.36 \pm 0.32$ & $-3.27 \pm 0.20^{\mathrm{a}}$ & $0.40 \pm 0.01^{\mathrm{a}}$ \\
\hline LHC & $-1.46 \pm 0.06$ & $3.35 \pm 0.27$ & $0.84 \pm 0.14^{a}$ & $-1.61 \pm 0.18$ & $3.64 \pm 0.22$ & $0.44 \pm 0.07^{\mathrm{a}}$ \\
\hline LAC & $-1.32 \pm 0.07^{a}$ & $3.35 \pm 0.16$ & $1.57 \pm 0.21^{\mathrm{a}}$ & $-1.65 \pm 0.11^{\mathrm{a}}$ & $3.67 \pm 0.19$ & $1.19 \pm 0.18^{\mathrm{a}}$ \\
\hline LPC & $-2.21 \pm 0.11$ & $3.03 \pm 0.19$ & $0.97 \pm 0.19^{a}$ & $-2.39 \pm 0.17$ & $3.30 \pm 0.27$ & $0.30 \pm 0.08^{\mathrm{a}}$ \\
\hline
\end{tabular}

$n=4$ per strain.

RHC, right horizontal canal; RAC, right anterior canal; RPC, right posterior canal; LHC, left horizontal canal; LAC, left anterior canal; LPC, left posterior canal.

${ }^{a}$ Statistically significant difference in position between strains; ANOVA, $p<0.05$. 
horizontal $(1.4 \times$ in $\mathrm{C} 57 \mathrm{Bl} / 6 \mathrm{~J}$ and $1.5 \times$ in $\mathrm{CBA} / \mathrm{CaJ})$ and posterior canals $(1.3 \times$ in both $\mathrm{C} 57 \mathrm{Bl} / 6 \mathrm{~J}$ and $\mathrm{CBA} / \mathrm{CaJ})$. The averaged coordinates for the centers of each canal are shown in Table 2. The maximum summed angle formed between the centroids above and below each canal and the regressed plane fit to that canal were $5.2^{\circ} \pm 0.8^{\circ}(\mathrm{CBA} / \mathrm{CaJ})$ and $5.9^{\circ} \pm 2.0^{\circ}$ $(\mathrm{C} 57 \mathrm{Bl} / 6 \mathrm{~J})$ for the posterior canal plane, $3.8^{\circ} \pm 1.5^{\circ}$ $(\mathrm{CBA} / \mathrm{CaJ})$ and $8.4^{\circ} \pm 3.1^{\circ}(\mathrm{C} 57 \mathrm{Bl} / 6 \mathrm{~J})$ for the horizontal canal plane, and $8.4^{\circ} \pm 1.7^{\circ}(\mathrm{CBA} / \mathrm{CaJ})$ and $12.6^{\circ} \pm 1.1^{\circ}(\mathrm{C} 57 \mathrm{Bl} / 6 \mathrm{~J})$ for the anterior canal plane.

Calculation of the orientation of the canal plane vectors showed that the length of at least one vector component was significantly different between the two strains for each canal, indicating a strain-specific difference in orientation of that canal. Table 3 presents the components of the averaged normal unit vectors for each canal in both the $\mathrm{CBA} / \mathrm{CaJ}$ and $\mathrm{C} 57 \mathrm{Bl} / 6 \mathrm{~J}$ strains. The same information is presented in graphical format in Fig. 4, with both individual unit vectors and averaged vectors displayed.

Angles between ipsilateral canal unit normal vectors and contralateral synergistic canal normal unit vectors (right anterior-left posterior; left anterior-right posterior; horizontal-horizontal) are reported in Table 4. Ipsilateral canals showed a range of deviations of $1.6^{\circ}-11.3^{\circ}(\mathrm{C} 57 \mathrm{Bl} / 6 \mathrm{~J})$ and $0.4^{\circ}-12.3^{\circ}$ $(\mathrm{CBA} / \mathrm{CaJ})$ from orthogonal. The horizontal-anterior canal pairs consistently formed acute angles, and the anterior-posterior and horizontal-posterior canal pairs formed obtuse angles. Synergistic canal pairs deviated from parallel in both strains, with the
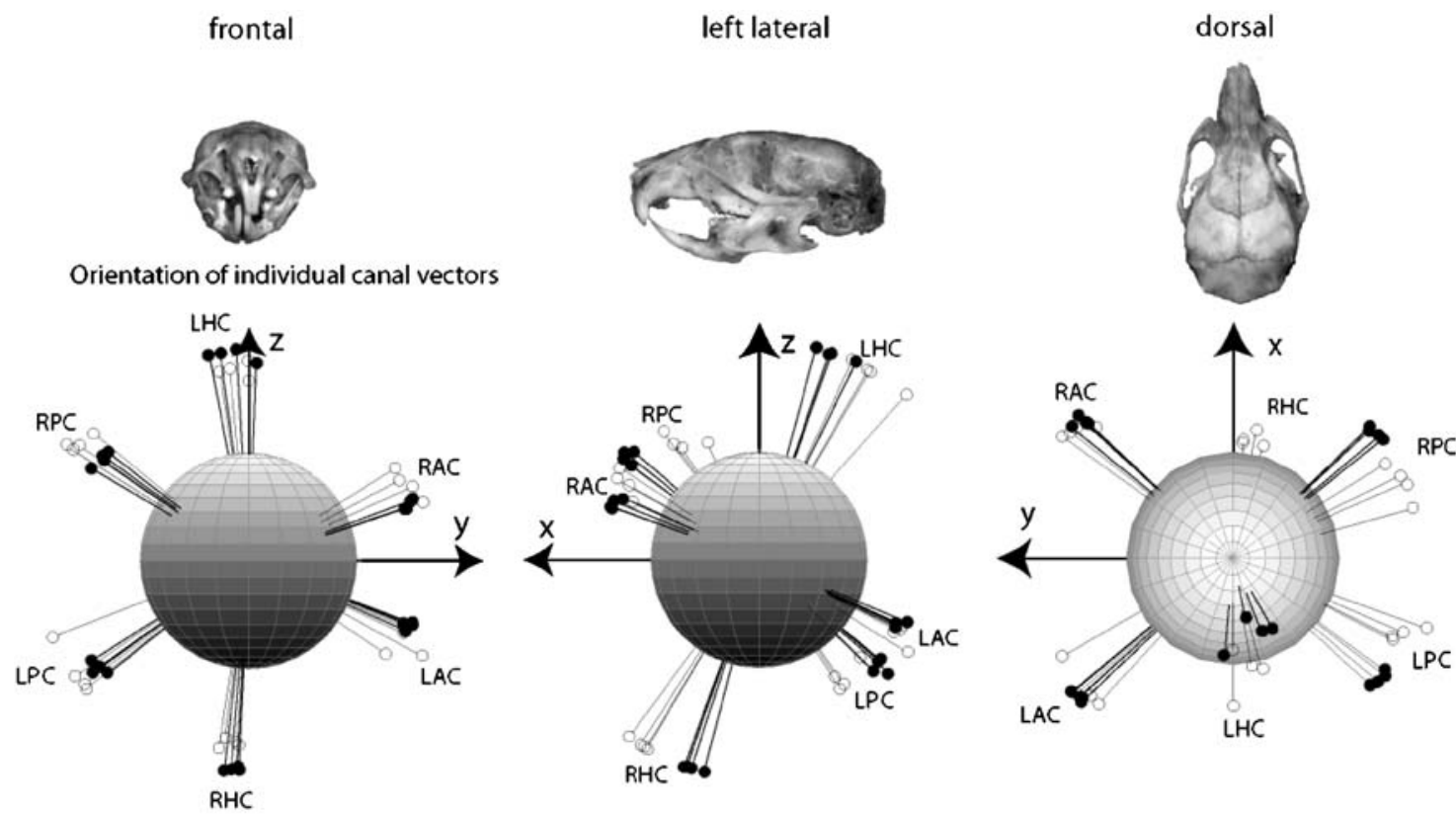

Orientation of average canal vectors
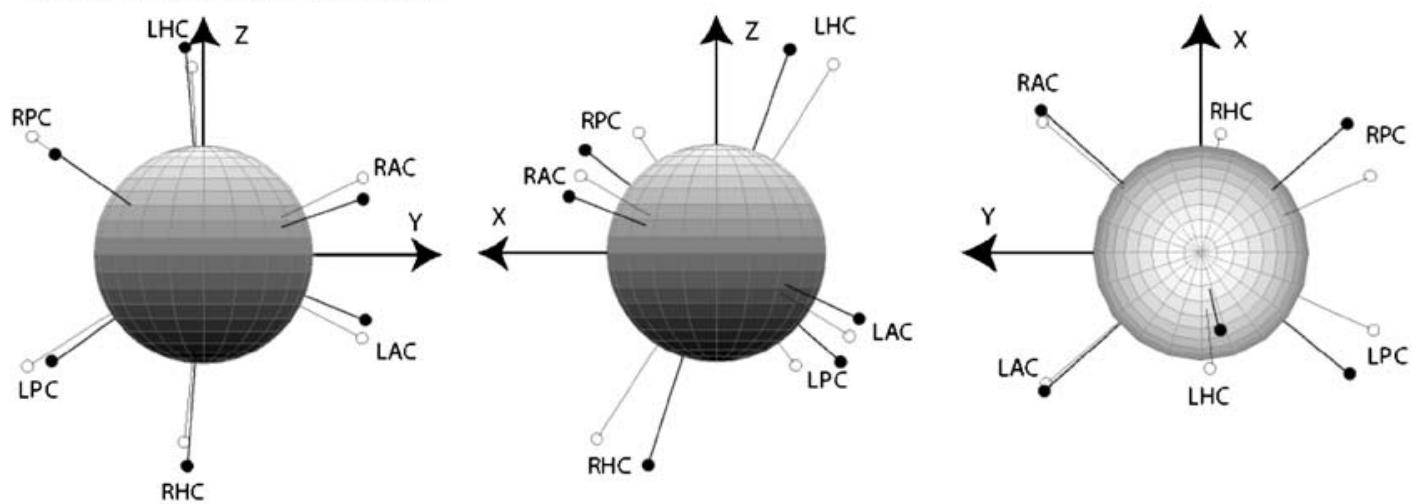

FIG. 4. Graphical representation of normal unit vectors. Top row: skull images indicating orientation of view for each column. Middle row: population of individual canal unit vectors plotted for CBA/Cal mice (filled symbols) and unit vectors plotted for C57Bl/6J mice (open symbols). Bottom row: average of vectors shown in middle row for CBA/CaJ mice (filled symbols) and for C57Bl/6J mice (open symbols). LHC, left horizontal canal; RHC, right horizontal canal; LAC, left anterior canal; RAC, right anterior canal; LPC, left posterior canal; RPC, right posterior canal. 
TABLE 4

Average angles in degrees between canal pairs in C57BI/6J and CBA/CaJ strains

\begin{tabular}{|c|c|c|c|c|c|c|}
\hline \multirow[b]{2}{*}{ Canal } & \multicolumn{3}{|c|}{ C57BL/6J mice $(n=4)$} & \multicolumn{3}{|c|}{ CBA/CaJ mice $(n=4)$} \\
\hline & Mean $\pm S D$ & $95 \% \mathrm{Cl}$ lower & 95\% Cl upper & Mean $\pm S D$ & 95\% Cl lower & 95\% Cl upper \\
\hline RHC vs. RAC & $91.55 \pm 1.02$ & 89.92 & 93.17 & $95.47 \pm 1.94^{\mathrm{a}}$ & 92.39 & 98.55 \\
\hline RHC vs. RPC & $101.26 \pm 0.96$ & 99.73 & 102.79 & $102.05 \pm 2.14$ & 98.64 & 105.46 \\
\hline RPC vs. RAC & $99.26 \pm 1.29$ & 97.20 & 101.32 & $88.94 \pm 1.98^{\mathrm{a}}$ & 85.79 & 92.09 \\
\hline LHC vs. LAC & $92.56 \pm 1.93$ & 89.49 & 95.64 & $96.82 \pm 5.73$ & 87.67 & 105.94 \\
\hline LHC vs. LPC & $101.17 \pm 0.97$ & 99.62 & 102.71 & $102.29 \pm 1.86$ & 99.32 & 105.26 \\
\hline LPC vs. LAC & $99.02 \pm 1.46$ & 96.69 & 101.34 & $89.65 \pm 2.51^{\mathrm{a}}$ & 85.67 & 93.64 \\
\hline $\mathrm{HC}$ vs. HC & $170.86 \pm 0.98$ & 169.29 & 172.43 & $169.58 \pm 3.80$ & 163.54 & 175.63 \\
\hline RAC vs. LPC & $162.34 \pm 1.43$ & 160.06 & 164.63 & $165.21 \pm 2.11$ & 161.84 & 168.57 \\
\hline LAC vs. RPC & $162.39 \pm 2.73$ & 158.05 & 166.73 & $169.00 \pm 1.24^{\mathrm{a}}$ & 167.03 & 170.97 \\
\hline
\end{tabular}

$n=4$ per strain. The upper and lower limits of $95 \%$ confidence intervals $(\mathrm{Cl})$ are shown.

RHC, right horizontal canal; RAC, right anterior canal; RPC, right posterior canal; LHC, left horizontal canal; LAC, left anterior canal; LPC, left posterior canal.

${ }^{a}$ Angles that differ significantly across strains (ANOVA, $p<0.05$ ).

canal pairs in the $\mathrm{C} 57 \mathrm{Bl} / 6 \mathrm{~J}$ strain at least $10^{\circ}$ away from parallel and in the $\mathrm{CBA} / \mathrm{CaJ}$ at least $7^{\circ}$ away from parallel.

For physiologic testing of responses of a particular semicircular canal, the canal is usually rotated into the earth-horizontal plane. Calculations of average angles of pitch and roll required to perform this maneuver for each strain of animal are displayed in Tables $5 \mathrm{~A}$ and $5 \mathrm{~B}$. Averages of $17.8^{\circ}(\mathrm{CBA} / \mathrm{CaJ})$ and $32.6^{\circ}(\mathrm{C} 57 \mathrm{Bl} / 6 \mathrm{~J})$ of pitch rotation about the $y$-axis were required to bring the horizontal canals into an earth-horizontal position. An alternate horizontal plane to the one used here is described by the line connecting the lambda and bregma suture (Slotnick and Leonard 1975). To facilitate positioning in situations where that plane is used as the basis for a stereotaxic system, the relationship between that plane and the plane used here was measured. The lambda-bregma horizontal was found to deviate anteriorly upward $4.3^{\circ} \pm 1.5^{\circ}(\mathrm{CBA} / \mathrm{CaJ})$ and $9.6^{\circ} \pm$ $5.2^{\circ}(\mathrm{C} 57 \mathrm{Bl} / 6 \mathrm{~J})$ from the horizontal plane defined by

\begin{tabular}{lcccc}
\hline \multicolumn{5}{c}{ TABLE 5A } \\
\hline \multicolumn{5}{c}{ Pitch and roll maneuvers for strain CBA/CaJ } \\
\hline Canal & Pitch & Direction & Roll & Direction \\
\hline RHC & 17.8 & ND & 4.0 & LED \\
RAC & 68.5 & NU & 45.9 & LED \\
RPC & 51.8 & NU & 41.7 & RED \\
LHC & 19.7 & ND & 4.6 & RED \\
LAC & 65.3 & NU & 45.8 & RED \\
LPC & 48.7 & NU & 42.5 & LED \\
\hline
\end{tabular}

Magnitude of rotations, in degrees, required to bring each semicircular canal into an earth-horizontal plane. Values are calculated assuming that pitch rotations are completed before roll rotations.

$\mathrm{RHC}$, right horizontal canal; RAC, right anterior canal; RPC, right posterior canal; LHC, left horizontal canal; LAC, left anterior canal; LPC, left posterior canal. Rotation directions: ND, rotated nose down; NU, rotated nose up; LED, rotated left ear down; RED, rotated right ear down. the centers of the external auditory meati and the point where the incisors emerge from the maxilla.

Prime direction vectors were calculated by taking the cross product of the unit normal vectors of each canal's ipsilateral canals. Comparison to the unit normal angles shows a clear deviation between the two vectors. For the $\mathrm{CBA} / \mathrm{CaJ}$ strain, the prime direction vectors are between $5.85^{\circ}$ and $15.00^{\circ}$ away from the normal unit vectors. The $\mathrm{C} 57$ mice deviate $9.91^{\circ}-14.90^{\circ}$ from the unit vectors. Angles between prime direction vectors were obtained by calculating their dot products. Ipsilateral prime directions are nonorthogonal, and angles between the prime directions of contralateral canal pairs are noncoplanar. These data are depicted in Tables $6 \mathrm{~A}$ and $6 \mathrm{~B}$.

\section{DISCUSSION}

Anatomic analysis of canal planes in mice shows that the canals are noncoplanar and nonorthogonal and

\begin{tabular}{lcccc}
\hline \multicolumn{5}{c}{ TABLE 5B } \\
\hline \multicolumn{5}{c}{ Pitch and roll for } \\
\hline Canal & Pitch & Direction & Roll & Direction \\
\hline RHC & 32.6 & ND & 4.9 & LED \\
RAC & 60.2 & NU & 46.0 & LED \\
RPC & 33.2 & NU & 50.6 & RED \\
LHC & 31.7 & ND & 3.1 & RED \\
LAC & 58.2 & NU & 45.0 & RED \\
LPC & 35.0 & NU & 52.0 & LED \\
\hline
\end{tabular}

Magnitude of rotations, in degrees, required to bring each semicircular canal into an earth-horizontal plane. Values are calculated assuming that pitch rotations are completed before roll rotations.

$\mathrm{RHC}$, right horizontal canal; RAC, right anterior canal; RPC, right posterior canal; LHC, left horizontal canal; LAC, left anterior canal; LPC, left posterior canal. Rotation directions: ND, rotated nose down; NU, rotated nose up; LED, rotated left ear down; RED, rotated right ear down. 


\section{TABLE 6A}

Average $X, Y$, and $Z$ components of prime direction vectors for $\mathrm{CBA} / \mathrm{CaJ}$ mice and $\mathrm{C} 57 \mathrm{Bl} / 6 \mathrm{~J}$ mice

\begin{tabular}{lcrc}
\hline Canal & $X \pm S D$ & $Y \pm S D$ & $Z \pm S D$ \\
\hline CBA/CaJ mice $(n=4)$ & & \\
RHC & $0.500 \pm 0.0290$ & $-0.147 \pm 0.0278$ & $-0.852 \pm 0.017$ \\
RAC & $0.679 \pm 0.0469$ & $0.712 \pm 0.0391$ & $0.165 \pm 0.0383$ \\
RPC & $0.666 \pm 0.0149$ & $-0.695 \pm 0.0191$ & $0.267 \pm 0.0145$ \\
LHC & $-0.545 \pm 0.0242$ & $-0.145 \pm 0.0153$ & $0.825 \pm 0.0168$ \\
LAC & $-0.687 \pm 0.0631$ & $0.694 \pm 0.0369$ & $-0.185 \pm 0.0954$ \\
LPC & $-0.653 \pm 0.008$ & $-0.695 \pm 0.0219$ & $-0.293 \pm 0.0567$
\end{tabular}

C57BI/6J mice $(n=4)$

$\begin{array}{llll}\text { RHC } & 0.656 \pm 0.028 & -0.205 \pm 0.023 & -0.724 \pm 0.0324\end{array}$

$\begin{array}{llll}\text { RAC } & 0.703 \pm 0.026 & 0.586 \pm 0.0729 & 0.391 \pm 0.068\end{array}$

$\begin{array}{llll}\text { RPC } & 0.572 \pm 0.063 & -0.690 \pm 0.0622 & 0.434 \pm 0.0427\end{array}$

$\begin{array}{llll}\text { LHC } & -0.655 \pm 0.082 & -0.166 \pm 0.074 & 0.727 \pm 0.075\end{array}$

$\begin{array}{llll}\text { LAC } & -0.706 \pm 0.106 & 0.572 \pm 0.0956 & -0.392 \pm 0.0717\end{array}$

LPC $\quad-0.573 \pm 0.009 \quad-0.703 \pm 0.067 \quad-0.405 \pm 0.108$

$n=4$ per strain.

RHC, right horizontal canal; RAC, right anterior canal; RPC, right posterior canal; LHC, left horizontal canal; LAC, left anterior canal; LPC, left posterior canal.

vary significantly from one strain to another. Data reported here are consistent with previous studies of the labyrinth. The radius of curvature averaged across all three canals in the mouse was found to be 0.859 $\mathrm{mm}$, comparable to the $0.94 \mathrm{~mm}$ reported by Jones and Spells (1963) for the jerboa mouse, a rodent in the related family Dipodidae. The radius of curvature of the anterior canals in both strains of mice was larger than the radii of the horizontal and posterior canals, a relationship that has been reported in other species including cat (Blanks et al. 1972), guinea pig (Curthoys et al. 1975), human (Blanks et al. 1975a; Spoor and Zonneveld 1998), rhesus and squirrel monkey (Blanks et al. 1985), and bird (Landolt and Correia 1980; Dickman 1996; Dickman and Fang 1996). The mouse canals are close to planar, with a maximum angle of divergence from the canal plane ranging from $3.8^{\circ}$ to $12.6^{\circ}$. This is approximately the same value determined for rhesus and squirrel monkeys, although these species appeared to have a more nonplanar anterior canal (Blanks et al. 1985) and less than that reported for toadfish (Ghanem et al. 1998) and pigeon (Landolt et al. 1975; Dickman 1996). Current limitations in imaging technology prevented an assessment of the minor radius and cross-sectional areas of the canals. Determination of these dimensions must await further improvements in imaging technology or the use of histologic techniques.

Much of the value of knowing the directions of canal planes lies in the assumption that canal planes represent the planes of maximum afferent sensitivity. Differences between the anatomic planes of the

\section{TABLE 6B}

Average angles in degrees between prime direction vector canal pairs in $\mathrm{C} 57 \mathrm{Bl} / 6 \mathrm{~J}$ and $\mathrm{CBA} / \mathrm{CaJ}$ strains

\begin{tabular}{lrr}
\hline \multicolumn{1}{c}{ Canal } & $\begin{array}{c}\text { C57BL/6J }(n=4), \\
\text { Mean } \pm S D\end{array}$ & $\begin{array}{r}C B A / C a J ~ \\
\text { Mean } \pm S D\end{array}$ \\
\hline RHC vs. RAC & $86.54 \pm 1.01$ & $84.63 \pm 2.14$ \\
RHC vs. RPC & $101.67 \pm 0.86$ & $102.03 \pm 2.12$ \\
RPC vs. RAC & $99.75 \pm 1.33$ & $90.13 \pm 2.17$ \\
LHC vs. LAC & $85.55 \pm 2.07$ & $83.05 \pm 6.07$ \\
LHC vs. LPC & $101.76 \pm 0.74$ & $102.45 \pm 2.03$ \\
LPC vs. LAC & $99.70 \pm 1.72$ & $91.14 \pm 3.31$ \\
HC vs. HC & $158.19 \pm 2.93$ & $162.81 \pm 2.57$ \\
RAC vs. LPC & $10.29 \pm 1.39$ & $8.37 \pm 3.62$ \\
LAC vs. RPC & $10.87 \pm 3.56$ & $7.84 \pm 1.38$ \\
\hline
\end{tabular}

$n=4$ per strain.

RHC, right horizontal canal; RAC, right anterior canal; RPC, right posterior canal; LHC, left horizontal canal; LAC, left anterior canal; LPC, left posterior canal.

canals and their planes of maximum sensitivity may arise from variance in the shape and size of the bony canal and the membranous duct, the departure of the canals from a strict toroidal shape, and the fluid mechanics of the endolymph system (Ghanem et al. 1998; Rabbitt 1999). Divergences in the two planes (anatomic and physiologic) have been reported for several species: $4^{\circ}$ for the horizontal canal and $5^{\circ}$ for the posterior canal in rhesus monkey (Reisine et al. 1988); $10^{\circ}$ for the horizontal canal and $8^{\circ}$ for the posterior canal in pigeons (Dickman 1996); and 6.5 for the horizontal canal and $10.2^{\circ}$ for the posterior canal in cats (Blanks et al. 1975b). In situations where canals are relatively nonplanar, angles between anatomic and physiologic canal planes may be higher. In the pigeon, the anatomic and physiologic anterior canal planes differed from $26^{\circ}$ to $56^{\circ}$, with the wide range due to the dihedral shape of the anterior canal in this animal (Dickman 1996). By calculating the weighted averages of the anatomically determined anterior canal planes, the difference between the pigeon's anatomic and physiologic canal planes became significantly less with a value of $6.3^{\circ}$ (Dickman 1996). Given the relative planarity of the mouse canals and the above results, their anatomic and afferent response planes are likely to lie close together. Afferent nerve recordings are required to confirm this hypothesis.

\section{Rotational vector direction}

Rotations in the plane of the horizontal canal are commonly performed during physiologic testing. The horizontal canals are tilted $17.8^{\circ}(\mathrm{CBA} / \mathrm{CaJ})$ and $32.6^{\circ}(\mathrm{C} 57 \mathrm{Bl} / 6 \mathrm{~J})$ anteriorly upward from the plane defined by the centers of the external auditory meati and the incisor bar. It may be argued that the differences in labyrinthine orientation between 
strains are simply because of the differences between the positions of the skull landmarks used to define the horizontal plane, and not because of the orientations of the canals within the skull. However, using the lambda-bregma line as an independent set of landmarks for a horizontal plane (Slotnick and Leonard 1975), ANOVA tests did not indicate an improved correlation between the vector components of the canal orientation vectors. The noncorrelation between the two strains of mice does not therefore appear to be an artifact of the particular reference frame used in this study.

\section{Orientation and orthogonality of canals}

Ipsilateral canal planes were found to deviate from orthogonality by $1.6^{\circ}-11.3^{\circ}$ in $\mathrm{C} 57 \mathrm{Bl} / 6 \mathrm{~J}$ mice and $0.4^{\circ}-12.3^{\circ}$ in $\mathrm{CBA} / \mathrm{CaJ}$ mice. This is in the range of other reported species, with the canals of the cat ranging from $0.38^{\circ}$ to $4.23^{\circ}$ (Blanks et al. 1972), turtle from $5.67^{\circ}$ to $9.83^{\circ}$ (Brichta et al. 1988), and albino rat from $0.2^{\circ}$ to $12.3^{\circ}$ (Cummins 1924). The $\mathrm{C} 57 \mathrm{Bl} / 6 \mathrm{~J}$ and $\mathrm{CBA} / \mathrm{CaJ}$ mice also show a deviation from parallel between contralateral, synergistic pairs of canals. A range of $7.84^{\circ}-11.81^{\circ}$ was observed in both of the strains of mice, which coincides with observations in other studies: $4.81^{\circ}-14.91^{\circ}$ in turtle (Brichta et al. 1988), $12.49^{\circ}-14.49^{\circ}$ in cat (Blanks et al. 1972), and $3.3^{\circ}-20.0^{\circ}$ in pigeons (Dickman 1996). Other studies show greater ranges of deviations from parallel: $11.1^{\circ}-33.2^{\circ}$ in toadfish (Ghanem et al. 1998) and $15.32^{\circ}-26.78^{\circ}$ in rabbit (Mazza and Winterson 1984). In some species, such as turtle (Brichta et al. 1988) and rabbit (Mazza and Winterson 1984), the orientation of the canals differs so significantly from orthogonal that it has been suggested that the animals are particularly sensitive to rotations in some directions relative to others. However, the deviations from orthogonal reported here in mice are unlikely to be large enough to constitute a strongly preferential sensitivity to movements in particular directions.

\section{Prime direction vectors and angles}

Nonorthogonal semicircular canals, such as the mouse canals described here, do not respond to rotations independent of one another, leading to difficulties interpreting the signals supplied by each canal. Rabbitt (1999) has therefore proposed that vestibular signals are understood in the frame of reference of prime directions. Rotations about a canal's prime direction vector should elicit a null response from its two ipsilateral canals. Only in the special case where the canals are perfectly orthogonal to each other the prime direction vectors are identical with each canal's unit normal vector. Prime direction vectors in both strains of mice studied here showed deviation from the unit normal vectors of between $5.85^{\circ}$ and $15.00^{\circ}$, reflecting the nonorthogonality of the mouse semicircular canals.

\section{Reliability of measurements}

The small sample size used here made correcting for multiple comparisons impractical in this study. This leads to the possibility that some of the anatomic differences between strains reported here would not prove to be statistically significant if larger samples were studied. Further study of the labyrinthine anatomy of these and other mouse strains will help determine which relationships are relatively constant among strains and which vary more widely.

\section{ACKNOWLEDGMENTS}

The authors wish to acknowledge funding support from Washington University's Hoopes Undergraduate Research Fund (DRC), the McDonnell Center for Higher Brain Function (TEH), and from National Institutes of Health NIDCD K08-DC006869 (TEH) and NIDCD P30 DC004665 to Washington University's Department of Otolaryngology-Head and Neck Surgery. We also thank Brian Uthgenannt for invaluable technical help scanning the specimens.

\section{REFERENCES}

Acampora D, Mazan S, Avantaggiato V, Barone P, Tuorto F, Lallemand Y, Brulet P, Simeone A. Epilepsy and brain abnormalities in mice lacking the Otxl gene. Nat. Genet. 14:218-222, 1996.

Ahituv N, Avraham KB. Auditory and vestibular mouse mutants: models for human deafness. J. Basic Clin. Physiol. Pharmacol. 11:181-191, 2000.

Alavizadeh A, Kiernan AE, Nolan P, Lo C, Steel KP, Bucan M. The wheels mutation in the mouse causes vascular, hindbrain, and inner ear defects. Dev. Biol. 234:244-260, 2001.

Anagnostopoulos AV. A compendium of mouse knockouts with inner ear defects. Trends Genet. 18:21-38, 2002.

Blanks RH, ToRigoe Y. Orientation of the semicircular canals in rat. Brain Res. 487:278-287, 1989.

Blanks RH, Curthoys IS, Markham CH. Planar relationships of semicircular canals in the cat. Am. J. Physiol. 223:55-62, 1972.

Blanks RHI, Curthoys IS, Markham CH. Planar relationships of the semicircular canals in man. Acta Oto-laryngol. 80:185-196, 1975a.

Blanks RHI, Estes MS, Markham CH. Physiologic characteristics of vestibular first order canal neurons in the cat. II. Response to constant angular acceleration. J. Neurophysiol. 38:1250-1268, $1975 \mathrm{~b}$.

Blanks RHI, Curthoys IS, Bennett ML, Markham CH. Planar relationships of the semicircular canals in rhesus and squirrel monkeys. Brain Res. 340:315-324, 1985. 
Brichta AM, Acuna DL, Peterson EH. Planar relations of semicircular canals in awake, resting turtles, Pseudemys scripta. Brain Behav. Evol. 32:236-245, 1988.

Cryns K, van Alphen AM, van Spaendonck MP, van de Heyning PH, Timmermans JP, de Zeeuw CI, van Camp G. Circling behavior in the Ecl mouse is caused by lateral semicircular canal defects. J. Comp. Neurol. 468:587-595, 2004.

Cummins $H$. The vestibular labyrinth of the albino rat: form and dimensions, and the orientation of the semicircular canals, cristae, and maculae. J. Comp. Neurol. 38:359-399, 1924.

Curthoys IS, Curthoys EJ, Blanks RH, Markham CH. The orientation of the semicircular canals in the guinea pig. Acta Otolaryngol. 80:197-205, 1975.

Della Santina CC, Potyagaylo V, Migliaccio Aa, Minor LB, Carey JP. Orientation of human semicircular canals measured by threedimensional multiplanar CT reconstruction. JARO 6:1-16, 2005.

De Zeeuw CI, Hansel C, Bian F, Koekoek SK, van Alphen AM, Linden DJ, OBerdick J. Expression of a protein kinase $\mathrm{C}$ inhibitor in Purkinje cells blocks cerebellar LTD and adaptation of the vestibulo-ocular reflex. Neuron 20:495-508, 1998.

DickMAn JD. Spatial orientation of semicircular canals and afferent sensitivity vectors in pigeons. Exp. Brain Res. 111:8-20, 1996.

DickMan JD, FAng Q. Differential central projections of vestibular afferents in pigeons. J. Comp. Neurol. 367:110-131, 1996.

EZURE K, GRAF W. A quantitative analysis of the spatial organization of the vestibulo-ocular reflexes in lateral- and frontal-eyed animals. I. Orientation of semicircular canals and extraocular muscles. Neuroscience 12:85-93, 1984.

Ghanem T, Rabbitt RD, Tresco PA. Three-dimensional reconstruction of the membranous vestibular labyrinth in the toadfish, Opsanus tau. Hear. Res. 124:27-43, 1998.

Haque A, Angelaki DE, Dickman JD. Spatial tuning and dynamics of vestibular semicircular canal afferents in rhesus monkeys. Exp. Brain Res. 155:81-90, 2003.

Наsнiмото S. Three-dimensional reconstruction and measurement of the human membranous semicircular canal. Nippon Jibi Inkoka Gakkai Kaiho 106:1-6, 2003.

Hawker K, Fuchs H, Angelis MH, Steel KP. Two new mouse mutants with vestibular defects that map to highly mutable locus on chromosome 4. Int. J. Audiol. 44:171-177, 2005.

Hurle B, Ignatova E, Massironi SM, Mashimo T, Rios X, Thalmann I, Thalmann R, Ornitz DM. Non-syndromic vestibular disorder with otoconial agenesis in tilted/mergulhador mice caused by mutations in otopetrin 1. Hum. Mol. Genet. 12:777-789, 2003.

Iсніјо H. Angles between left and right vertical semicircular canals. Nippon Jibi Inkoka Gakkai Kaiho 105:1138-1142, 2002.

Johnson KR, Zheng QY, ERwaY LC. A major gene affecting agerelated hearing loss is common to at least ten inbred strains of mice. Genomics 70:171-180, 2000.

Jones GM, Spells KE. A theoretical and comparative study of the functional dependence of the semicircular canal upon its physical dimensions. P Roy Soc Lond B Bio 157:403-419, 1963.

Khan Z, Carey JP, Park HJ, Lehar M, Lasker D, Jinnah HA. Abnormal motor behavior and vestibular dysfunction in the stargazer mouse mutant. Neuroscience 127:785-796, 2004.

Kiernan Ae, Erven A, Voegeling S, Peters J, Nolan P, Hunter J, Bacon Y, Steel KP, Brown SD, GUeNET JL. ENU mutagenesis reveals a highly mutable locus on mouse Chromosome 4 that affects ear morphogenesis. Mamm. Genome 13:142-148, 2002.

Koekkoek SK, van Alphen AM, Galjart N, van den Berg J, Grosveld F, De Zeeuw CI. Gain adaptation and phase dynamics of compensatory eye movements in mice. Genes Funct. 1:175-190, 1997.
Kozel PJ, Friedman RA, Erway LC, Yamoah N, Liu LH, Riddle T, Duffy JJ, Doetschman T, Miller Ml, Cardell El, Shull GE. Balance and hearing deficits in mice with a null mutation in the gene encoding plasma membrane $\mathrm{Ca}^{2+}$-ATPase isoform 2. J. Biol. Chem. 273:18693-18696, 1998.

Landolt JP, Correia MJ. Neurodynamic response analysis of anterior semicircular canal afferents in the pigeon. J. Neurophysiol. 43:1746-1770, 1980.

Landolt JP, Correia MJ, Young ER, Cardin RP, Sweet RC. A scanning electron microscopic study of the morphology and geometry of neural surfaces and structures associated with the vestibular apparatus of the pigeon. J. Comp. Neurol. 159:257-287, 1975.

Lee H-Y, Camp AJ, Callister RJ, Brichta AM. Vestibular primary afferent activity in an in vitro preparation of the mouse inner ear. J. Neurosci. Methods 145:73-87, 2005.

Longo-Guess CM, Gagnon LH, Cook SA, Wu J, Zheng QY, Johnson KR. A missense mutation in the previously undescribed gene Tmhs underlies deafness in hurry-scurry hscy mice. Proc. Natl. Acad. Sci. U. S. A. 102:7894-7899, 2005.

Mazza D, Winterson B. Semicircular canal orientation in the adult resting rabbit. Acta Oto-laryngol. 98:472-480, 1984.

Paffenholz R, Bergstrom RA, Pasutto F, Wabnitz P, Munroe RJ, Jagla W, Hieinzmann U, Marquardt A, Bareiss A, Laufs J, Russ A, Stumm G, Schimenti JC, Berstrom DE. Vestibular defects in headtilt mice result from mutations in Nox3, encoding an NADPH oxidase. Genes Dev. 18:486-491, 2004.

Park HJ, LASKer DM, Minor LB. Discharge properties of otolith afferents in the normal C5BL/ 6 mouse. Assoc. Res. Otolaryngol. Abs. 990, 2005.

RABBiTT RD. Directional coding of three-dimensional movements by the vestibular semicircular canals. Biol. Cybern. 80:417-431, 1999.

ReIsine H, Simpson JI, HenN V. A geometric analysis of semicircular canals and induced activity in their peripheral afferents in the rhesus monkey. Ann. N.Y. Acad. Sci. 545:10-20, 1988.

Sato H, Sando I, Takahashi H. Computer-aided three-dimensional measurement of the human vestibular apparatus. Otolaryngol. Head Neck Surg. 107:405-409, 1992.

Sherwood N, Timiras P. A Stereotaxic Atlas of the Developing Rat Brain. University of California Press, Berkeley, CA, 1970.

Slotnick B, Leonard C. A Stereotaxic Atlas of the Albino Mouse Forebrain. U.S. Dept. of Health, Education, and Welfare, Rockville, MD, 1975.

Spoor F, Zonneveld F. Comparative review of the human bony labyrinth. Am. J. Phys. Anthropol. S27:211-251, 1998.

Stahl JS, James R, Oommen B, Hoebeck F, De Zeeuw C. Eye movements of the murine $\mathrm{P} / \mathrm{Q}$ calcium channel mutant rocker, and the impact of aging. J. Neurophysiol. 91:2066-2078, 2004.

Stahl JS, van Alphen AM, De Zeeuw CI. A comparison of video and magnetic search coil recordings of mouse eye movements. J. Neurosci. Methods 99:101-110, 2000.

Sun JC, Van Alphen A, Bohne B, De Zeeuw C. Shaker-1 mice show an optokinetic reflex, but no vestibulo-ocular reflex. Ann NY Acad Sci 942:492, 2001.

van Alphen AM, Stahl JS, De Zeeuw CI. The dynamic characteristics of the mouse horizontal vestibulo-ocular and optokinetic response. Brain Res. 890:296-305, 2001.

Vetter De, Mann JR, Wangemann P, Liu J, McLaughlin KJ, Lesage F, Marcus DC, Lazdunski M, Heinemann SF, Barhanin J. Inner ear defects induced by null mutation of the isk gene. Neuron 17:1251-1264, 1996. 